\title{
Clinical Profile and Mutations Associated with Multiple Endocrine Neoplasia-Type1 (MEN1) and their First-Degree Relatives at Risk of Developing MEN1: A Prospective Study
}

\author{
Authors \\ Asha Hesarghatta Shyamasunder ${ }^{1} \mathbb{D}$, Rekha Pai ${ }^{2} \mathbb{D}$, Hemalatha Ramamoorthy², Dhananjayan Sakthi², Marie Therese

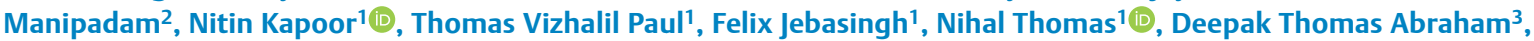 \\ Mazhuvanchary Jacob Paul ${ }^{3}$, Ari George Chacko ${ }^{4}$, Krishna Prabhu4 ${ }^{4}$, Simon Rajaratnam ${ }^{1}$
}

\author{
Affiliations \\ 1 Department of Endocrinology, Diabetes and Metabolism, \\ Christian Medical College, Vellore, Tamil Nadu, India \\ 2 Department of Pathology, Christian Medical College, \\ Vellore, Tamil Nadu, India \\ 3 Department of Endocrine Surgery, Christian Medical \\ College, Vellore, Tamil Nadu, India \\ 4 Department of Neurosurgery, Christian Medical College, \\ Vellore, Tamil Nadu, India
}

Key words

MEN1, 3' and 5' UTR, CDKN1B, CaSR, hyperparathyroidism

received 12.11 .2020

accepted after revision $\quad 18.02 .2021$

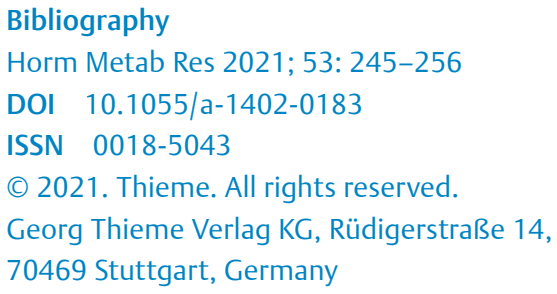

Correspondence

Professor Dr. Asha Hesarghatta Shyamasunder

Department of Endocrinology

Diabetes and Metabolism

Christian Medical College

Vellore 632004

Tamil Nadu

India

Tel.: + 914162282528 , Fax: + 914162232035

hsasha75@gmail.com

\section{ABSTRACT}

Multiple Endocrine Neoplasia type-1 (MEN1) is an autosomal dominant disorder with a combined occurrence of tumours of parathyroid glands, pancreatic islets, and anterior pituitary. About $90 \%$ of these patients carry mutations in the MEN1 gene, though the spectrum is not well defined in India. Forty clinically suspected cases of MEN1 were enrolled prospectively over six years; 32 patients ( 23 index-cases and 9 affected relatives) with $\geq 2$ classical endocrine tumours of MEN1 were considered definite, and 8 were categorised as 'MEN1-like'. Details of their clinical presentation, treatment and mutational analysis including MEN1 gene, $3^{\prime}$ and 5' untranslated regions (UTR) of MEN1, CDKN1B, and CaSR genes were collated. Asymptomatic first-degree relatives were also screened. Among the 32 definite MEN1 patients, all had primary hyperparathyroidism, 22 (68.7\%) had gastroentero-pancreatic neuroendocrine tumours, and 21 (66\%) had pituitary adenoma. Of the 23 definite index-cases, 13 (56.5\%) carried mutations in the MEN1 gene. Five of 9 affected first-degree relatives (55.5\%), and 4 of 10 asymptomatic relatives ( $40 \%$ ) also had MEN1 mutations. Seven of 10 MEN1 mutation-negative definite index-cases harboured p.V109G polymorphism in the CDKN1B gene. All 8 MEN1-like cases were negative for mutations and large deletions in MEN1, mutations in $3^{\prime}$ and $5^{\prime}$ UTR of MEN1 and CDKN1B genes. The study has helped to clearly document the pattern of mutations among Indian MEN1 patients. However, the absence of MEN1 mutation in $\sim 44 \%$ of cases and the presence of p.V109G polymorphism in CDKN1B gene raise the question whether such polymorphisms could independently contribute to pathogenesis.

\section{Introduction}

Multiple endocrine neoplasia type-1 (MEN1) is a rare autosomal dominant disorder characterised by a predilection for the occurrence of two or more of the following endocrine tumours- parathyroid adenomas, gastroentero-pancreatic neuroendocrine tumours (GEP NETs), and pituitary adenomas, along with adrenal adenomas and neuroendocrine tumours of the thymus, lung, and stomach [1]. MEN1 syndrome is often termed as 'classical' if there are at least two endocrine tumours, namely, parathyroid, pituitary or GEP NETs. Parathyroid tumours are the most common, seen in about $90 \%$, while $30-70 \%$ harbour pancreatic tumours and $30-40 \%$ pituitary tumours [2]. MEN1 is associated with a significantly higher 
mortality rate, especially in cases of malignant GEP NETs, thymic and bronchial carcinoids where the risk of death is increased threefold [3]. MEN1 is known to be associated with variable penetrance, though the disease might present with differing clinical features even among members of the same family [4].

MEN1 is caused by germline inactivating mutations in the MEN1 gene, consisting of 10 exons, that encodes the menin protein [5]. Over 1000 germline mutations have been identified, including large deletions, splice-site mutants and mutations in the $5^{\prime}$ and $3^{\prime}$ untranslated regions (UTRs) [2]. Large deletions in the MEN1 gene are often identified using the multiplex ligation dependant probe amplification (MLPA) assay [6]. Identification of mutations in the MEN1 gene is strongly recommended for a definitive genetic diagnosis of MEN1 and asymptomatic first-degree relatives [2]. However, about 5-10\% patients who strictly meet the clinical criteria have no identifiable mutation [7]. About $5 \%$ of the MEN1 cases may represent phenocopies where they mimic MEN1 in clinical presentation, but carry mutations in unrelated genes like CDKN1B or CaSR $[6,8]$. The need for such comprehensive genetic testing limits it to fewer laboratories with the expertise and infrastructure to undertake this kind of testing.

\section{Aim}

Given the paucity of data from India, we decided to prospectively characterise patients with a clinical diagnosis of MEN1 looking at the clinical presentation, the genotype-phenotype association and the pattern of mutations involving the MEN1 gene, 5' and 3' untranslated regions (UTR) of MEN1 gene, CaSR and the CDKN1B gene.

\section{Subjects and Methods}

\section{Subjects}

Between 2013 and 2019, 31 index cases and 9 affected first degree relatives with MEN1 were enrolled prospectively at our centre. Subjects with two of the three classical endocrine tumours described with MEN1, that is, parathyroid adenomas, GEP NETs and anterior pituitary tumours were labelled as definite MEN1 ( $n=32$, index cases23). Eight index patients who had one classical endocrine tumour associated with MEN1, with either a non-endocrine tumour associated with MEN1 or history of one of the MEN1 associated tumour in a first degree relative, or early onset primary hyperparathyroidism (<30 years) were classified as MEN1-like cases ( $>$ Fig. 1) [2].

Demographic data, details of clinical presentation, biochemical investigations, imaging, treatment modalities, and outcomes of management were recorded. Standard recommended protocols were followed for the diagnosis and management of MEN1 associated parathyroid, pituitary and pancreatic tumours [9-17]. ${ }^{68} \mathrm{Ga}$ DOTATATE PET-CT scan was performed when there was a suspicion of metastatic pancreatic neuroendocrine tumours (NETs) or carcinoid tumour. Patients with metastatic GEP NETs were treated with ${ }^{177}$ Lu DOTATATE peptide receptor targeted radionuclide therapy (PRRT) or chemotherapy. Patients with adrenocortical tumours detected on abdominal CT scans had assessment of their functional status, and surgery was recommended for functioning tumours or those $\geq 4 \mathrm{~cm}$ in size. Foregut carcinoids were treated with surgery followed by chemotherapy, radiation therapy and/or PRRT with 177/utetium DOTATATE.

Institutional review board and ethics committee approval was obtained to conduct the study (IRB Min number 8141, dated 19.12.2012). Ten $\mathrm{ml}$ of peripheral venous blood was drawn for genetic testing, after obtaining consent. Screening was extended to all the first-degree relatives "at-risk" of carrying these mutations, once an index case was identified.

\section{Molecular genetic analysis}

DNA for mutational analysis was isolated for each patient using the QIAGEN QIAamp blood mini kit (Qiagen, India) and the DNA was quantitated using the Nanodrop (NanoDrop technologies, USA). Polymerase chain reaction (PCR) for nine exons (exons 2-10) of the MEN1 gene was performed using published primer sequences [18]. The sense and antisense strands were sequenced using the automated DNA sequencer (ABI PRISM 310 genetic analyzer) with the ABI PRISM BigDye Terminator Cycle Sequencing Ready Reaction Kit (Applied Biosystems, USA). Mutational analysis was performed by comparing the sequence with the wild type (Ref Seq NM_130799). All family members recruited into the study were screened only for the mutation seen in the index case. Further, samples from the index cases negative for MEN1 mutation by PCR-sequencing were characterised for large deletions using the MLPA assay (MRC, Holland, Amsterdam, The Netherlands) and eventually for 5' and 3' UTR of MEN1 gene (new primers were designed). Those who did not carry MEN1 mutations or large deletions were further screened for mutations in CDKN1B [19] and CaSR [20] genes.

Statistical analysis was performed with SPSS version 21 (IBM SPSS Statistics for Windows, Version 21.0. Armonk, NY: IBM Corp). Mean and standard deviation (SD) of continuous variables, and the frequency of categorical variables were calculated. Independent

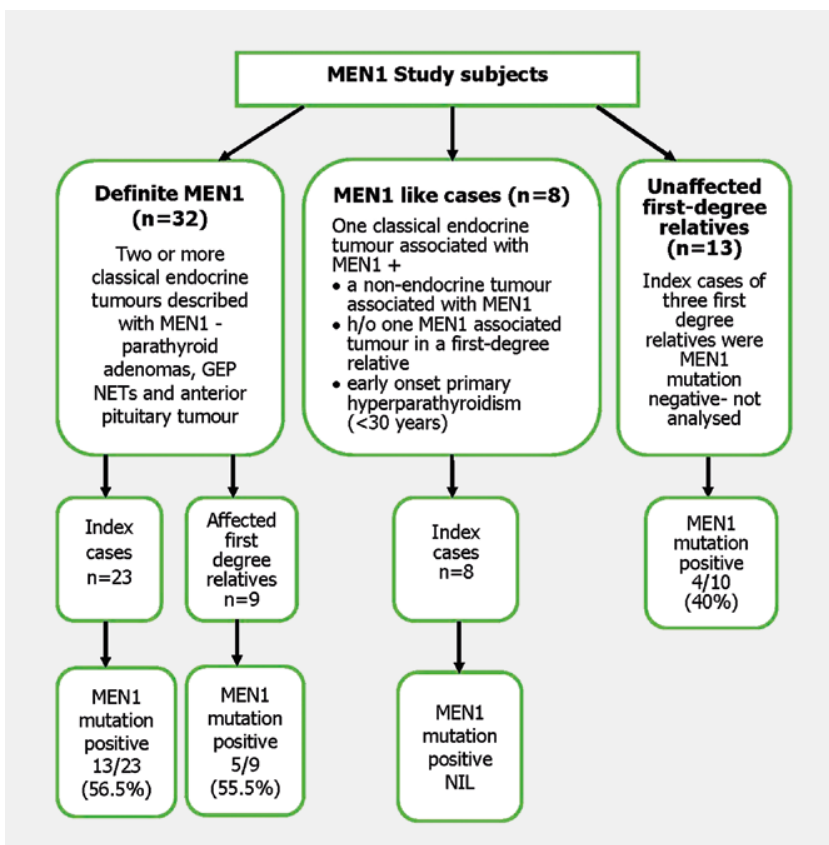

- Fig. 1 Description of the MEN1 study subjects. 
samples $t$-test was used to compare the continuous variables between the two groups.

\section{Results}

\section{Demographics and clinical presentation}

Forty patients with multiple endocrine neoplasia 1 (MEN1) were prospectively recruited including 32 definite MEN1 cases ( 15 male and 17 female) - 23 index cases and 9 first degree relatives, and 8 MEN1like cases. The subjects were described with their family number and labelled I for index cases (e. g., F2I) or R for relatives (e. g., F5R1).

Among the definite MEN1 cases, 16 index cases (70\%) had family history of MEN1; including classical endocrine tumours associated with MEN1 in the first-degree relatives of five cases, and presumptive MEN1 tumours in the relatives based on clinical history in eleven others (i. e., renal calculi in multiple family members, or early death of a parent with abdominal malignancy). The mean age at diagnosis of the first MEN1 endocrine tumour was 32.7 years (SD 14.4 , range $14-71$ years). The first endocrine tumour at presentation was a pituitary tumour in 15 patients (47\%), primary hyperparathyroidism in 8 (25\%), GEP NETs in $9(28 \%)$ and bronchial carcinoid in one patient (3\%).

The commonest endocrine tumour among definite MEN1 cases $(n=32)$ was primary hyperparathyroidism in 32 patients (100\%), followed by GEP NETs in 22 patients (68.7\%) and pituitary adenomas in 21 patients (65.6\%). The GEP NETs included 7 insulinomas, 8 gastrinomas, nine non-functioning tumours and one causing ectopic ACTH dependent Cushing's syndrome. Two subjects had insulinoma and non-functioning pancreatic NETs (F1I and F13I), while one had a large gastrinoma and multiple insulinomas (F5I) ( $\triangleright$ Table 1). Eight patients ( $25 \%$ ) had nodular adrenal masses of which 5 were bilateral tumours. Four patients had carcinoid tumours (12.5\%), three were thymic carcinoids and one was a bronchial carcinoid. Seven patients ( $22 \%$ ) had leiomyomas, 5 were uterine myomas, and one each in the oesophagus and hepatico-duodenal omentum. Multiple collagenomas were noted in 8 patients ( $25 \%$ ), facial angiofibroma in one patient, lipomas in four and café-au-lait macules in five patients [21]. Table 1 and $>$ Table 2 list the tumours and mutation profile of the familial and sporadic definite MEN1 cases respectively.

\section{Parathyroid tumours}

The mean age at diagnosis of primary hyperparathyroidism was 36.4 years (SD 14.2, range 17-71 years). Twenty of 32 patients (62.5\%) were asymptomatic and were diagnosed during screening for MEN1. Two patients had abdominal pain due to renal calculi, ten had bone pain of whom one had a vertebral fracture. The biochemical features, surgical outcomes and histopathology of the tumours are described in $\triangleright$ Table 3 . Of the 26 patients who underwent ultrasound screening for localisation of parathyroid adenomas, 14 had enlargement of multiple parathyroid glands, 10 had enlargement of a single parathyroid gland and in two patients the tumour could not be localised. Eighteen patients had 99mTc Sestamibi scan of which 17 scans localised the tumour - a single hyperfunctioning parathyroid in nine patients, and multiple hyperfunctioning glands in 8 patients. Among 15 patients who had both ${ }^{99 m T c}$ Sestamibi and ultrasound scans, 12 had concordant lesions. Twen- ty-six patients ( $81 \%$ ) had surgery for primary hyperparathyroidism with cervical thymectomy; three patients had staged surgery for excision of multiple parathyroid tumours as MEN1 was not suspected during their initial evaluation. Three patients are awaiting surgery, two have defaulted and one is on medical management with cinacalcet as she declined surgery (F11). Three patients who had undergone sub-total parathyroidectomy (excision of 3 or $3 \frac{1}{2} 2$ parathyroid glands) [22] at our centre had recurrence of parathyroid adenomas ten, nine and four years after initial surgery respectively. One patient underwent repeat surgery and two patients are on medical treatment.

\section{Pituitary tumours}

Twenty-one patients had pituitary adenomas. The mean age at diagnosis was 27.6 years (SD 10.6, range $14-55$ years). Eleven patients had presented with headache, 6 had visual impairment, one had $3^{\text {rd }}$ cranial nerve palsy and two had presented with pituitary apoplexy. The remaining were incidentally detected on pituitary MRI during evaluation for MEN1. Eight patients had symptoms of hypogonadism in the form of amenorrhoea or erectile dysfunction. Seven patients had pituitary microadenomas, 12 had macroadenomas of which 7 were invasive tumours, and two patients who had previously been treated at another hospital had no residual tumour on imaging. Sixteen patients had prolactinomas, two had growth hormone $(\mathrm{GH})$ secreting tumours, one had a $\mathrm{GH}$ and prolactin co-secreting tumour, and two patients had non-functioning pituitary adenomas. Three patients with prolactinoma had undergone surgery for excision of the tumours 20 years before the diagnosis of MEN1. Thirteen patients with prolactinoma were treated with cabergoline and one was treated earlier at another centre with bromocriptine; 13 patients responded to medical treatment, one patient with prolactinoma resistant to cabergoline was advised surgery, and one cabergoline responder underwent surgery for CSF rhinorrhoea. All three patients with $\mathrm{GH}$ and $\mathrm{GH}$-prolactin co-secreting tumours underwent surgery, and have remained in remission. Among the non-functioning pituitary tumours, one underwent surgery and the other patient with a microadenoma is on follow-up.

\section{Gastroentero-pancreatic NETs}

Among 22 patients with GEP NETs, 8 patients had gastrinomas. Six patients had mild hypergastrinemia with serum gastrin $<1000 \mathrm{pg} /$ $\mathrm{ml}$ without any duodenal or pancreatic NET identified on CT scan abdomen and/or MRI of the pancreas. Among patients with gastrinoma, one had recurrent peptic ulcers, and 7 had dyspeptic symptoms. The mean serum gastrin level was 8941 (SD 7631) ng/l. The hormonal profile, imaging characters and treatment of these patients is described in Table 4.

Seven patients had insulinomas, all of them presented with fasting hypoglycemia. The mean plasma glucose was $35.4 \mathrm{mg} / \mathrm{dl}$ (SD 9.3), the corresponding mean plasma insulin level was $11.9 \mu \mathrm{lU} / \mathrm{ml}$ (SD 7.5), and the mean C-peptide level was $2.63 \mathrm{ng} / \mathrm{ml}$ (SD 1.2). Four patients had multiple lesions and three patients had a single tumour on imaging. One patient (F5 index) had a large gastrinoma at the pancreatic tail and multiple insulinomas in the neck and uncinate process of pancreas with liver metastases. The details of their biochemical parameters, imaging findings and management are described in $>$ Table 4. 

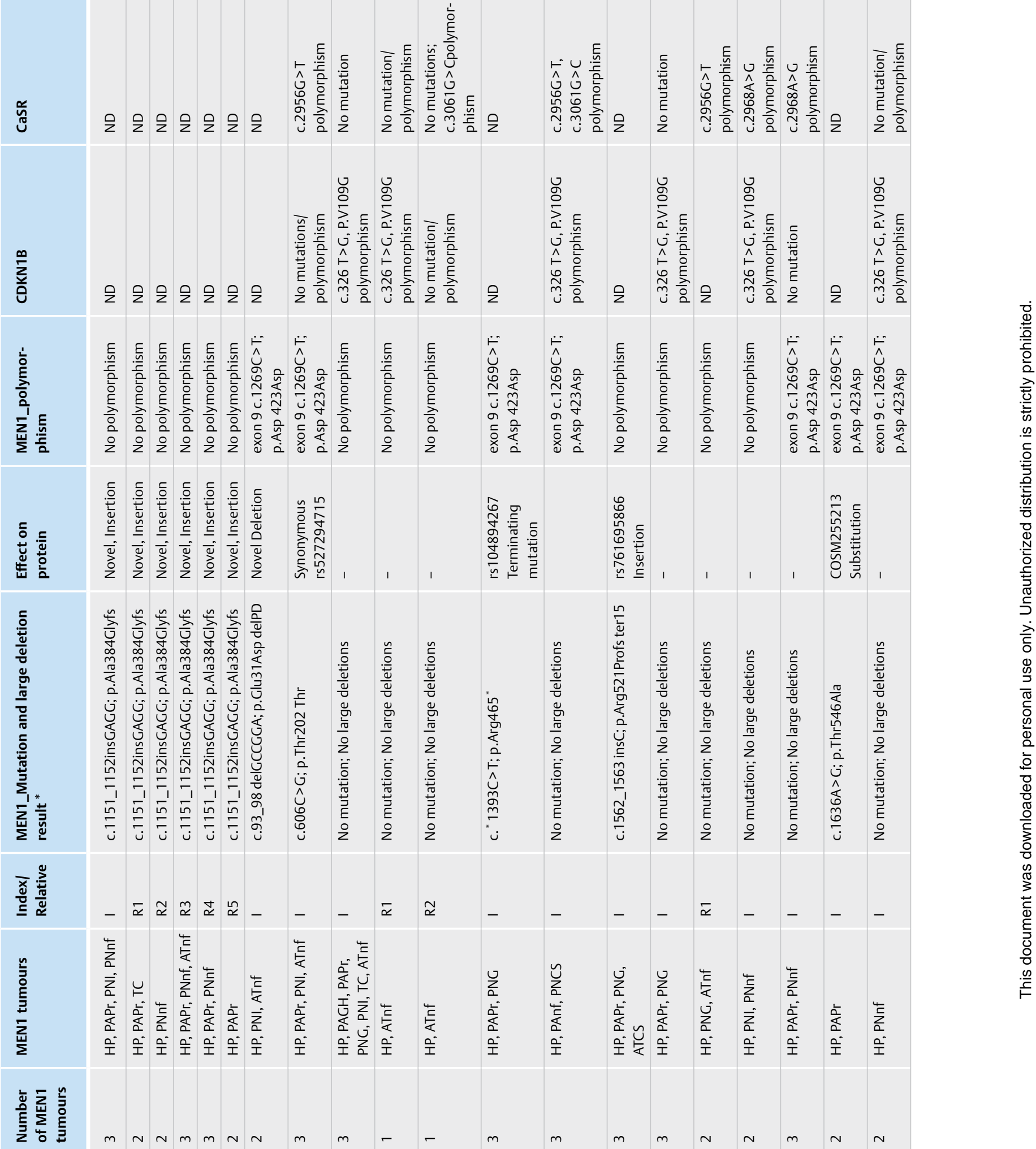

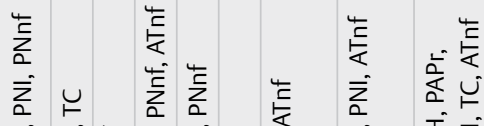

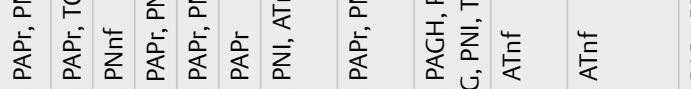

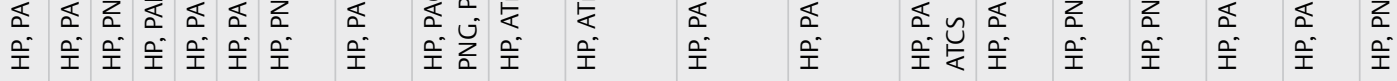

$\frac{n}{4}$
$+\frac{0}{5}$
$\stackrel{5}{\frac{5}{c}}$

ㅇำ

우

$\stackrel{\infty}{\sim}$

$\bar{m}$

m) ำ

敦旁

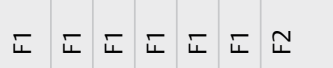

눈는 는

is

要 


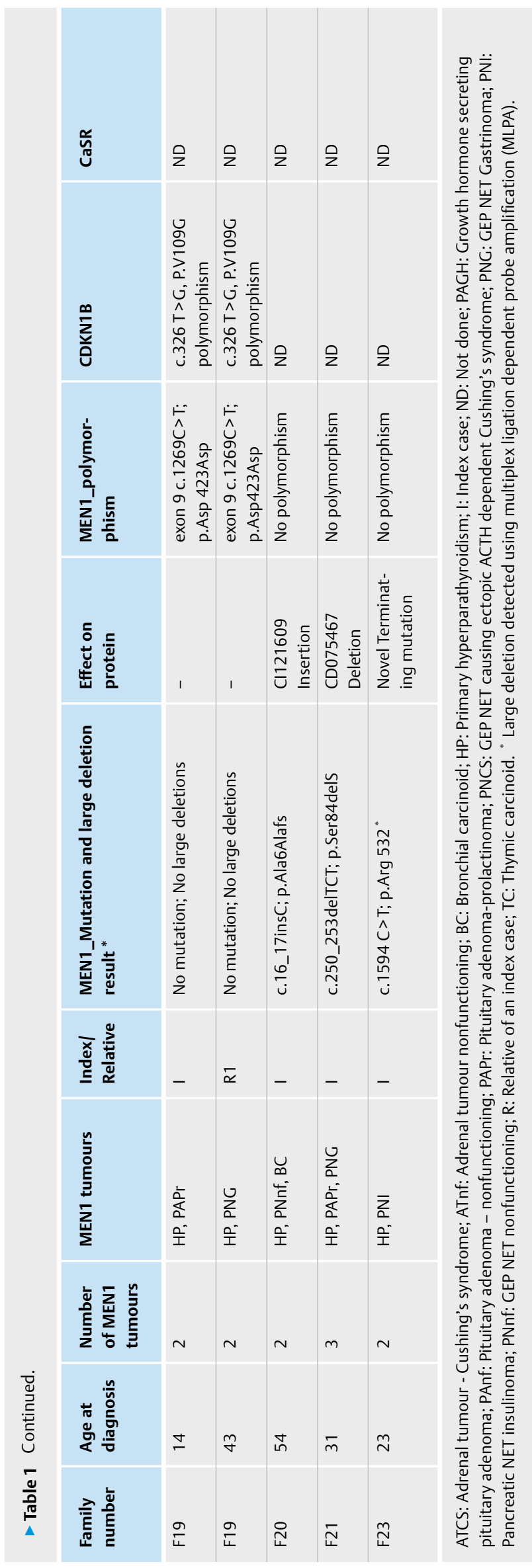

One patient had multiple pancreatic NETs with ACTH dependent Cushing's syndrome which had progressed over two years. He underwent near total pancreatectomy at another centre, and the Cushing's syndrome is in remission. Nine patients had non-functioning GEP NETs. One patient with an inoperable tumour involving the tail of the pancreas with liver and lymph node metastases was treated with chemotherapy and ${ }^{177}$ lutetium DOTATATE PRRT; he is doing well on follow up. Another patient with a $4 \times 3 \mathrm{~cm}$ non-functioning pancreatic NET underwent surgery. Six patients with lesions $<2 \mathrm{~cm}$ at initial presentation have been on regular follow-up; two of them were advised surgery as the tumours had increased in size to more than $2 \mathrm{~cm}$. One patient who had distal pancreatectomy earlier for insulinoma developed non-functioning GEP NETs in the head $(31 \times 27 \mathrm{~mm})$ and uncinate process $(9 \mathrm{~mm})$, she is also awaiting repeat surgery ( $\vee$ Table 4$)$.

\section{Adrenal, thymic, and bronchial tumours}

Eight patients had nodular adrenal masses, five of them were bilateral. One patient had ACTH independent Cushing's syndrome which was well controlled with ketoconazole, others were non-functioning. Four patients had carcinoid tumours, three had thymic carcinoids and one had a bronchial carcinoid. Two of the three thymic carcinoids were large tumours $(>5 \mathrm{~cm})$; one underwent surgery (F1R1), and histopathological examination confirmed the diagnosis of thymic neuroendocrine carcinoma. He received adjuvant chemotherapy, radiotherapy and ${ }^{177}$ lutetium DOTATATE PRRT, and is in remission. Another patient with a large thymic tumour had spontaneous regression of thymic enlargement after surgery for his growth hormone secreting pituitary adenoma (F5 index). The third patient with thymic carcinoid declined surgery, and was lost to follow-up. The patient with bronchial carcinoid underwent surgical treatment and is in remission.

\section{MEN1-like cases}

Eight patients had MEN1-like presentation, the mean age at diagnosis was 38.2 years (SD 23.8, range $14-73$ years). Three patients had pituitary adenomas, three had GEP NETs, and two had primary hyperparathyroidism. The reason for inclusion of these patients as MEN1-like cases for genetic testing is described in $\mathbf{~ T a b l e ~} \mathbf{5}$. Three patients had positive family history of one MEN1 associated endocrine tumour in a first-degree relative. One patient had early onset primary hyperparathyroidism at 21 years of age, and was screened for MEN1 mutation, despite the absence of other manifestations or family history of MEN1.

\section{Mortality}

During a mean follow-up period of 5.0 years (SD 4.2 years), two patients with definite MEN1 had sudden cardiac death at home (F10I and F12R1), and another patient with MEN1-like syndrome died of metastatic glucagonoma (F27).

\section{Mutational profiles}

Among the 23 index cases with definite MEN1, 13(56.5\%) had mutations in the MEN1 gene. One had a previously described (rs527294715; c.606C> G; p.Thr202 Thr) synonymous variation, that was not considered a mutation. Mutation positive subjects tended to be diagnosed at a younger age compared to mutation 
Table 2 MEN1 associated tumours and mutations in sporadic MEN1 cases.

\begin{tabular}{|c|c|c|c|c|c|c|c|c|}
\hline $\begin{array}{l}\text { Family } \\
\text { number }\end{array}$ & $\begin{array}{l}\text { Age at } \\
\text { diagnosis }\end{array}$ & $\begin{array}{l}\text { Number } \\
\text { of MEN1 } \\
\text { tumours }\end{array}$ & $\begin{array}{l}\text { MEN1 } \\
\text { tumours }\end{array}$ & $\begin{array}{l}\text { MEN1 Mutation and } \\
\text { large deletion result }\end{array}$ & $\begin{array}{l}\text { Effect on } \\
\text { protein }\end{array}$ & $\begin{array}{l}\text { MEN1_polymor- } \\
\text { phism }\end{array}$ & CDKN1B & CaSR \\
\hline F3 & 22 & 2 & HP, PAPr & $\begin{array}{l}\text { c.643_646delACAG; } \\
\text { p.Thr215Serfs }\end{array}$ & $\begin{array}{l}\text { Frameshift } \\
\text { Novel }\end{array}$ & $\begin{array}{l}\text { exon } 9 \text { c. } 1269 C>T \text {; } \\
\text { p.Asp } 423 \text { Asp }\end{array}$ & ND & ND \\
\hline F6 & 22 & 3 & $\begin{array}{l}\text { HP, PAPr, } \\
\text { PNG }\end{array}$ & $\begin{array}{l}\text { c.1562_1563insC; } \\
\text { p.Arg521fs ter33 }\end{array}$ & $\begin{array}{l}\text { Frameshift } \\
\text { Novel }\end{array}$ & $\begin{array}{l}\text { exon } 9 \text { c. } 1269 C>T \\
\text { p.Asp } 423 \text { Asp }\end{array}$ & ND & ND \\
\hline F8 & 25 & 2 & HP, PAPr & $\begin{array}{l}\text { c. }{ }^{*} 1402 \text { G >T; p. } \\
\text { Glu468* }\end{array}$ & $\begin{array}{l}\text { Terminating } \\
\text { mutation } \\
\text { Novel }\end{array}$ & No polymorphism & ND & ND \\
\hline F11 & 71 & 2 & HP, PNI & $\begin{array}{l}\text { C. } 1200+1 \text { dupG } \\
\text { p. } 400+1 \text { dupG }\end{array}$ & $\begin{array}{l}\text { Splice site } \\
\text { mutation } \\
\text { Novel }\end{array}$ & No polymorphism & ND & ND \\
\hline F16 & 23 & 3 & $\begin{array}{l}\text { HP, PAPr, } \\
\text { PNnf }\end{array}$ & $\begin{array}{l}\text { c. } 160 \_161 \text { insTC; } \\
\text { p.lle54llefs ter } 100\end{array}$ & $\begin{array}{l}\text { Frameshift } \\
\text { Novel }\end{array}$ & No polymorphism & ND & ND \\
\hline F18 & 55 & 2 & HP, PAGH & $\begin{array}{l}\text { No mutation; No large } \\
\text { deletions }\end{array}$ & - & No polymorphism & $\begin{array}{l}\text { c.326 T>G, P. } \\
\text { V109G polymor- } \\
\text { phism }\end{array}$ & ND \\
\hline F22 & 23 & 2 & HP, PAGH & $\begin{array}{l}\text { No mutation; No large } \\
\text { deletions }\end{array}$ & - & No polymorphism & $\begin{array}{l}\text { ND- sample } \\
\text { insufficient }\end{array}$ & $\begin{array}{l}\text { ND-sample } \\
\text { insufficient }\end{array}$ \\
\hline
\end{tabular}

ATCS: Adrenal tumour - Cushing's syndrome; ATnf: Adrenal tumour nonfunctioning; BC: Bronchial carcinoid; HP: Primary hyperparathyroidism; ND: Not done; PAGH: Growth hormone secreting pituitary adenoma; PAnf: Pituitary adenoma - nonfunctioning; PAPr: Pituitary adenoma-prolactinoma: PNG: GEP NET gastrinoma: PNI: Pancreatic NET insulinoma; PNnf: GEP NET nonfunctioning; TC: Thymic carcinoid.

negative subjects though this was not significant (mean age 29.4 vs. 31.5 years, $p=0.74)$. Among index cases who gave a family history of MEN1, 8 of 16 cases ( $50 \%$ ) had MEN1 gene mutations, three of which were novel mutations ( $\triangleright$ Table 1 ). Interestingly, mutation positivity was higher among those without family history of MEN1 where 5 of 7 (71.4\%) were positive, and all carried novel mutations that have not been described before ( $\triangleright$ Table 2 ). In all $61 \%$ of the mutations reported were novel. The mutational spectrum in this study included frameshift (61\%), terminating (23\%) and substitutions/splice site mutations ( $8 \%$ each). Eleven index patients had all the three classical tumours described with MEN1, and among them six (54.5\%) carried MEN1 mutations, while 7 of 12 index patients (58.3\%) with two classical tumours associated with MEN1 carried mutations in the MEN1 gene. The mutation positivity was higher with the combination of parathyroid tumours and GEP NETs (4/5; $80 \%$ ) compared to patients with parathyroid and pituitary tumours (3/6; 50\%). There was no genotype-phenotype correlation; 6 members of $\mathrm{F} 1$ carried the same mutation, but had different combinations of MEN1 tumours with varied severity of manifestations. Among the nine affected relatives tested, five subjects from one family (F1) carried the same mutation as in the index case, the remaining four were mutation negative similar to their respective index cases ( $\triangleright$ Table 1 ). Ten index patients (43.5\%) had MEN1 gene polymorphisms ( $\triangleright$ Table 1 and $\triangleright$ Table 2 ). None of the patients characterised in this study had large exonic/gene deletions detected by MLPA assay. Further, 10 index cases (43.5\%) who did not have mutations in the MEN1 exonic region were checked for mutations in the $5^{\prime}$ and $3^{\prime}$ untranslated regions of the MEN1 gene, CDKN1B and CaSR genes and found to be negative though several of them carried polymorphisms ( $\triangleright$ Table 1 and $\triangleright$ Table 2). None of the eight MEN1-like cases carried mutations in the MEN1 exonic or untranslated regions, 6 had polymorphisms in the MEN1 gene ( $\triangleright$ Table 5).

Thirteen asymptomatic first-degree relatives of definite MEN1 cases provided blood samples for genetic testing. Three were relatives of MEN1 mutation negative index patients and hence, their samples were not tested for MEN1 mutations. Four (40\%) of 10 relatives of MEN1 mutation positive index cases carried MEN1 exonic region mutations similar to their respective index cases - one of four from F1, one of two from F7 and one each from F2 and F15. Two relatives have been on periodic screening for MEN1 related tumours and have not manifested any MEN1 tumours until the last follow-up, one from F2 is a four-year-old child, and her parents have been counselled about the need for screening for MEN1 associated tumours after the age of five years. One asymptomatic relative was lost to follow-up.

\section{Discussion}

We present the clinical and mutational profile of 40 patients with MEN1 from 31 families, including 31 index cases (23 definite and eight MEN1-like cases), nine affected relatives and 13 asymptomatic first-degree relatives. The study highlights the challenges in clinical management and the importance of a multidisciplinary approach for successful diagnosis and treatment of MEN1. To the best of our knowledge this is the largest case series of MEN1 from India, where genetic testing for MEN1 has been performed in-house, comple- 


\begin{tabular}{|c|c|c|c|c|c|}
\hline & 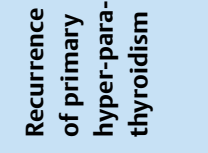 & 1 & $\overline{\overline{\bar{C}}}$ & 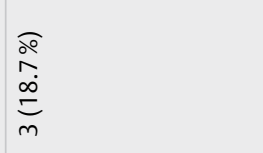 & 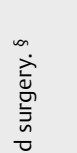 \\
\hline & 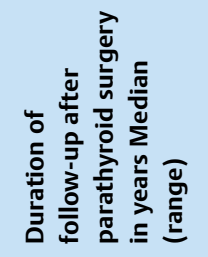 & $\overline{\bar{E}}$ & 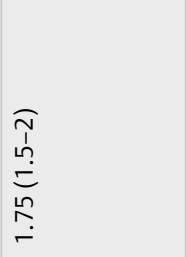 & $\begin{array}{l}\frac{\partial}{a} \\
\overline{1} \\
\tilde{n} \\
e \\
\\
\text { nn }\end{array}$ & 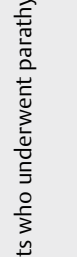 \\
\hline & 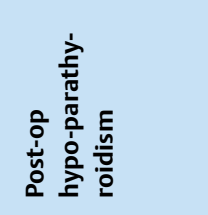 & 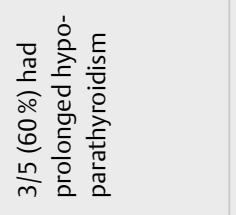 & 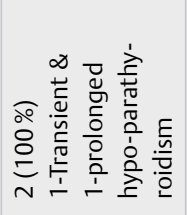 & 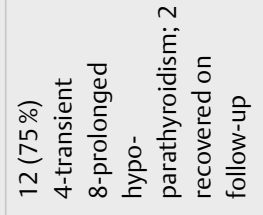 & 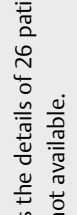 \\
\hline & 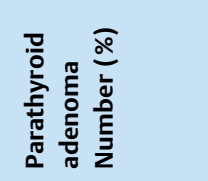 & 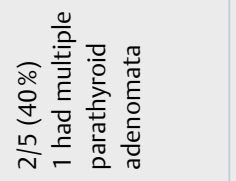 & 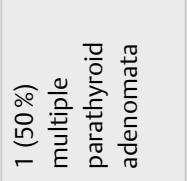 & 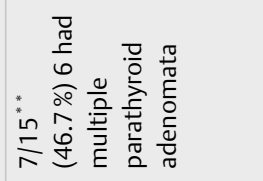 & 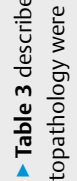 \\
\hline & 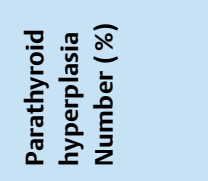 & 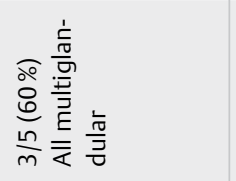 & 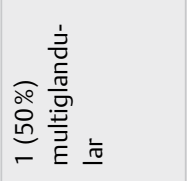 & 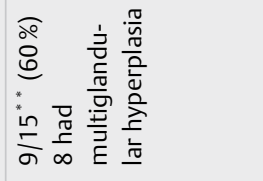 & 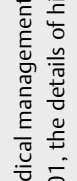 \\
\hline 芯 & 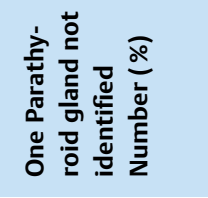 & 1 & 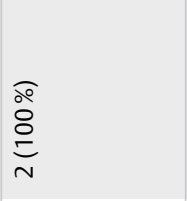 & $\overline{\bar{E}}$ & 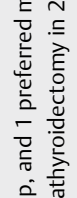 \\
\hline 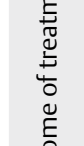 & 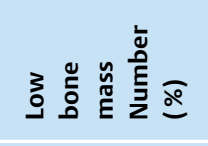 & $\frac{\text { o }}{\stackrel{5}{\frac{1}{n}}}$ & 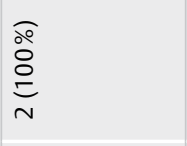 & m & 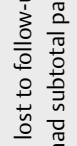 \\
\hline 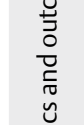 & 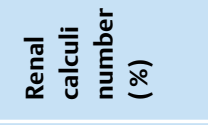 & $\begin{array}{l}\text { ळo } \\
\infty \\
m \\
m\end{array}$ & $\overline{\bar{C}}$ & 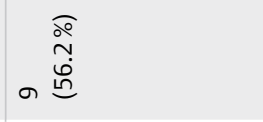 & 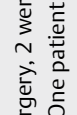 \\
\hline 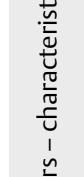 & 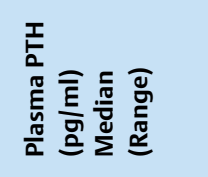 & 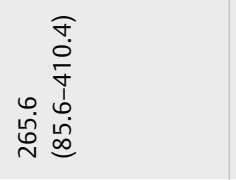 & 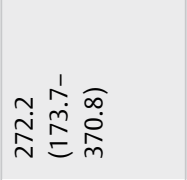 & 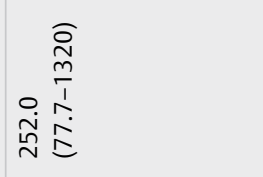 & 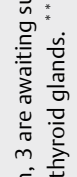 \\
\hline 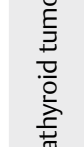 & 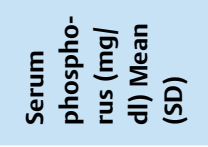 & $\begin{array}{l}\widehat{\sigma} \\
\stackrel{0}{0} \\
\stackrel{0}{i} \\
i\end{array}$ & 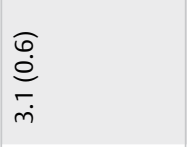 & 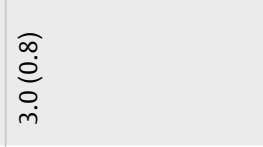 & 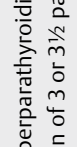 \\
\hline 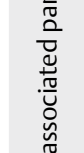 & 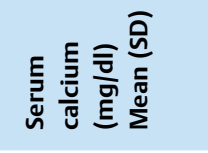 & 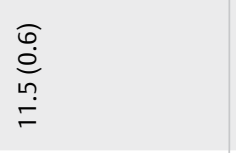 & 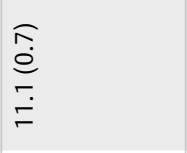 & 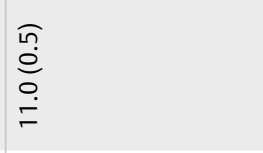 & 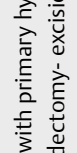 \\
\hline 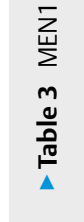 & 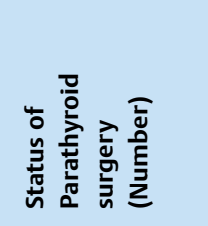 & 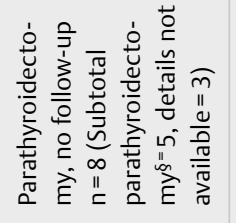 & 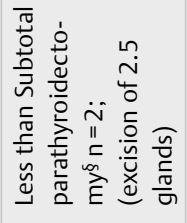 & 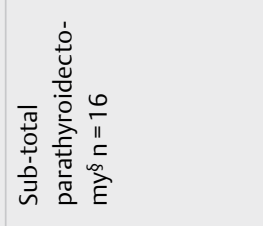 & 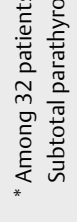 \\
\hline
\end{tabular}




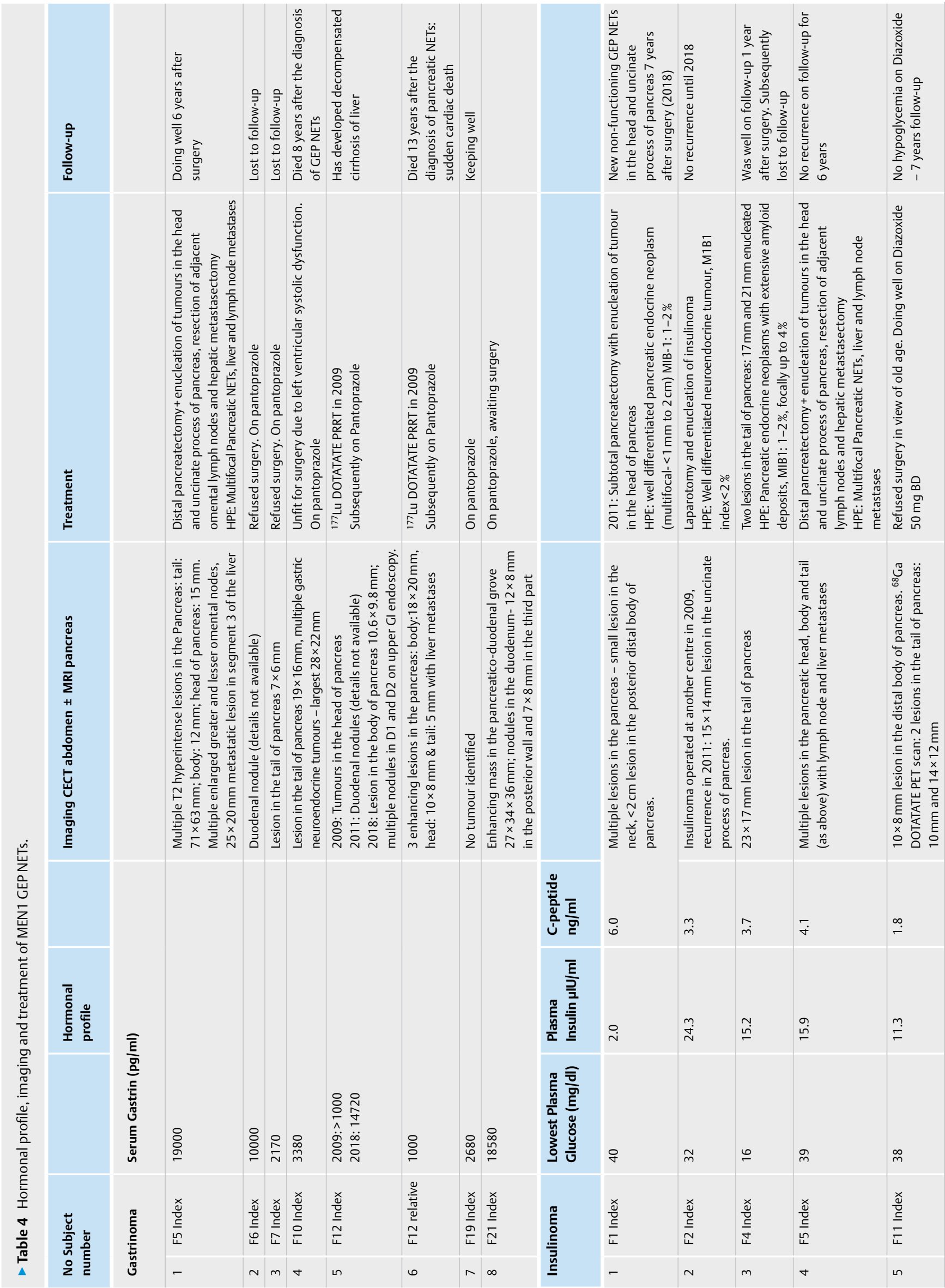




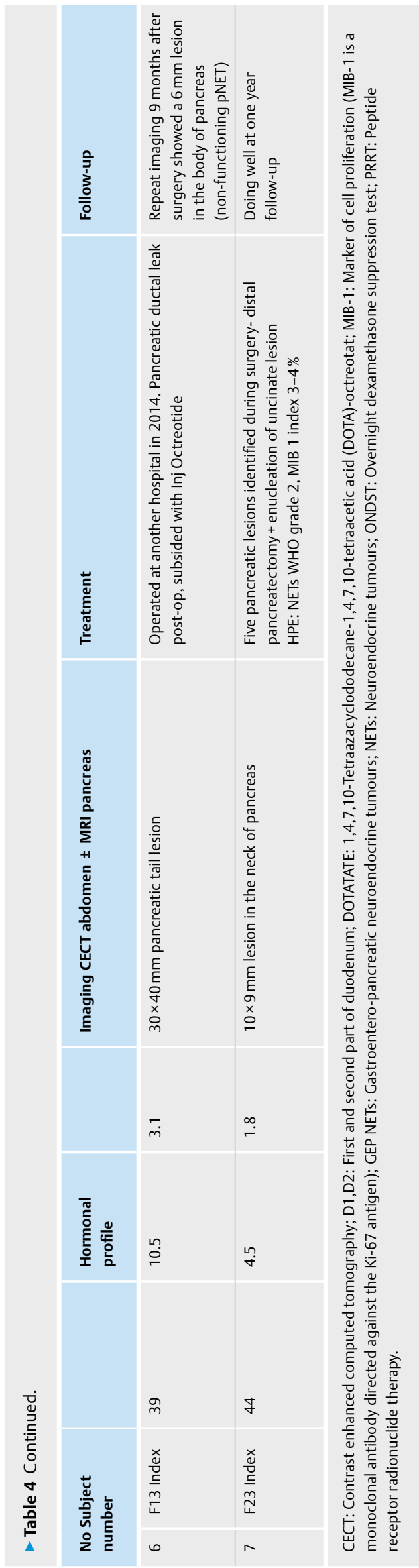

mented by testing for large deletions by MLPA, MEN1 UTRs, and sequencing for CDKN1B and CaSR genes to identify phenocopies.

\section{Familial MEN1}

Seventy percent of our definite MEN1 cases had a positive family history, similar to the Japanese and French series where 72 and $64 \%$ respectively had familial MEN1 $[23,24]$. Other series have reported lesser frequency of familial MEN1- 57\% in an Australian series [25], 29\% in a Swedish series [26] and 17\% from Western India [27].

\section{Clinical presentation and outcomes of treatment}

The most common presenting tumour of MEN1 was pituitary tumour $(47 \%)$ in our study, though others reported GEP NETs as the first presenting tumour [23,27], likely due to referral bias. Primary hyperparathyroidism recurred in $19 \%$ of our patients who were available for follow-up after sub-total parathyroidectomy. A Dutch series reported recurrence rates of $53 \%$ following excision of fewer than three parathyroids, $17 \%$ after sub-total parathyroidectomy and $19 \%$ after total parathyroidectomy [28], while an American study reported relapse in $24 \%$ after subtotal parathyroidectomy and $13 \%$ after total parathyroidectomy [29]. Ninety percent (19/21) of the pituitary tumours were functional, with a predominance of prolactinomas ( $76 \%$ ) in our series, similar to the French series, where $72 \%$ were functioning pituitary tumours [30]. One of our eight patients with gastrinoma, 6 of 7 patients with insulino$\mathrm{ma}$, and one of nine patients with non-functioning GEP NET had surgical excision. The role of surgery, and the extent of surgical exploration of gastrinomas is controversial because of the inability to achieve consistent biochemical cure [31]. Resection of the most severely affected part of the pancreas, with enucleation of concomitant NETs $>0.5 \mathrm{~cm}$ in the preserved pancreas is recommended for insulinomas associated with MEN1 [32]. Most small non-functioning pancreatic NETs $<2 \mathrm{~cm}$ remain stable over time [33] and have low risk of disease-specific mortality; hence conservative management is recommended [17]. Though DOTA PET scan provides a panoramic view of the various tumours associated with MEN1, it is expensive, and does not have greater sensitivity as compared to cross sectional imaging for pancreas, pituitary, and adrenals, and has low sensitivity to localise parathyroid tumours [34].

\section{MEN1 mutational analysis}

Though genetic testing is recommended for definitive diagnosis, it yields negative results in a significant proportion of patients with a clinical diagnosis of MEN1. Among our definite MEN1 index cases $(n=23)$, mutations in the MEN1 gene were detected in $56.5 \%$ of the patients; none of the eight MEN1-like cases carried mutations. The overall mutation positivity among 31 index cases (definite and MEN1-like) was $42 \%$. Similar mutation frequency of $42 \%$ was reported by a study from UK including 142 MEN1 cases [35], and a lower frequency of $24 \%$ was reported in a Swedish cohort [26]. Some large studies have reported higher MEN1 mutation positivity of $69-83 \%[23,24,36]$. Mutation positivity rates have been reported to be higher in familial cases ( $>87 \%$ ) when compared to sporadic cases $(31-82 \%)$ [23, 24, 26]. In our series, the MEN1 mutation positivity was $50 \%$ among familial cases and $71 \%$ among sporadic cases of definite MEN1. However, the mutation positivity reported in our study is certainly lesser than a series from Western 
- Table 5 MEN1 associated tumours and mutations in MEN1-like Index cases.

\begin{tabular}{|c|c|c|c|c|c|c|c|}
\hline $\begin{array}{l}\text { Family } \\
\text { num- } \\
\text { ber }\end{array}$ & $\begin{array}{l}\text { Age } \\
\text { at } \\
\text { diag- } \\
\text { nosis }\end{array}$ & $\begin{array}{l}\text { Number } \\
\text { of MEN1 } \\
\text { tumours }\end{array}$ & MEN1 tumours & $\begin{array}{l}\text { Reason for genetic } \\
\text { testing }\end{array}$ & $\begin{array}{l}\text { MEN1 } \\
\text { mutation }\end{array}$ & $\begin{array}{l}\text { MEN1 polymor- } \\
\text { phism }\end{array}$ & CDKN1B \\
\hline F24 & 14 & 1 & PACD & $\begin{array}{l}\text { Mother had } \\
\text { insulinoma }\end{array}$ & No mutation & $\begin{array}{l}\text { exon } 9 \text { c. } 1269 \mathrm{C}>\mathrm{T} \\
\text { p.Asp } 423 \mathrm{Asp}\end{array}$ & No mutation \\
\hline F25 & 14 & 1 & PAPr & $\begin{array}{l}\text { Mother had lung } \\
\text { carcinoid }\end{array}$ & No mutation & $\begin{array}{l}\text { exon } 9 \text { c. } 1269 \text { C > T; } \\
\text { p.Asp } 423 \text { Asp }\end{array}$ & No mutation \\
\hline F26 & 73 & 1 & PNG_lost follow-up & $\begin{array}{l}\text { Brother had } \\
\text { pancreatic tumour }\end{array}$ & No mutation & No polymorphism & No mutation \\
\hline F27 & 71 & 1 & PNGI, Meningioma & $\begin{array}{l}\text { Glucagonoma with } \\
\text { liver metastases, and } \\
\text { left parietal } \\
\text { meningioma }\end{array}$ & No mutation & $\begin{array}{l}\text { exon } 9 \text { c. } 1269 C>T \\
\text { p.Asp } 423 \text { Asp }\end{array}$ & No mutation \\
\hline F28 & 49 & 1 & $\begin{array}{l}\text { PNnf, TC_lost } \\
\text { follow-up }\end{array}$ & $\begin{array}{l}\text { Patient has PNETs } \\
\text { and thymic tumour, } \\
\text { family } \mathrm{h} / \mathrm{o} \text { pituitary } \\
\text { tumour in } 2 / 7 \\
\text { siblings and father }\end{array}$ & No mutation & $\begin{array}{l}\text { exon } 9 \text { c. } 1269 C>T \text {; } \\
\text { p.Asp } 423 \text { Asp }\end{array}$ & $\begin{array}{l}\text { c.326 T>G, } \\
\text { P.V109G } \\
\text { polymorphism }\end{array}$ \\
\hline F29 & 21 & 1 & HP & $\begin{array}{l}\text { Primary hyperparath- } \\
\text { yroidism at young } \\
\text { age }\end{array}$ & No mutation & $\begin{array}{l}\text { exon } 9 \text { c. } 1269 \text { C > T; } \\
\text { p.Asp } 423 \text { Asp }\end{array}$ & $\begin{array}{l}\text { c.326 T>G, } \\
\text { P.V109G } \\
\text { polymorphism }\end{array}$ \\
\hline F30 & 28 & 1 & $\operatorname{PAPr}(1997), \mathrm{BC}$ & $\begin{array}{l}\text { Pituitary adenoma } \\
\text { with Bronchial } \\
\text { carcinoid }\end{array}$ & No mutation & $\begin{array}{l}\text { exon } 9 \text { c. } 1269 C>T \\
\text { p.Asp } 423 \text { Asp }\end{array}$ & No mutation \\
\hline F31 & 36 & 2 & HP, PNnf (prob) & $\begin{array}{l}\text { Hyperparathy- } \\
\text { roidism: LIPA, h/o } \\
\text { distal pancreatecto- } \\
\text { my in } 1989 \text {, } \\
\text { recurrent tumour } \\
\text { operated in } \\
\text { 1996-probable NET }\end{array}$ & No mutation & No polymorphism & No mutation \\
\hline
\end{tabular}

India with $85 \%$ positivity, though they performed mutational analysis in a subset of their cases [27].

Our results are also slightly in variance to what is reported in the context of mutation positivity based on the number of tumours. In a large MEN1 cohort, those with all three classic MEN1 endocrine tumours were more likely to have mutations when compared to those with two or one classical MEN1 tumour (79 vs. 37 vs. $15 \%$ ) [35]. In our study, $54.5 \%$ of the patients with all three classical tumours were mutation positive when compared to $58.3 \%$ with two tumours. Further, none of the MEN1-like cases were mutation positive in this study; it is fairly well established that MEN1-like cases have lower mutation frequency ranging from 6-31\%, with a study from UK finding none to be positive [23, 24, 35]. It can be argued that the higher population prevalence of primary hyperparathyroidism and pituitary adenomas could lead to a sporadic co-occurrence of these tumours, a plausible reason for lesser MEN1 mutation positivity in these patients when compared to the combination of hyperparathyroidism with GEP NETs [8]. In a recent study by
Backman et al, only three of the 14 cases that were negative by Sanger sequencing for MEN1 were found to carry MEN1 gene mutations by whole genome sequencing. The authors therefore contend that the absence of mutations in the remaining cases could perhaps be explained as a chance co-occurrence of endocrine tumours in a single patient [37]. Also, the presence of somatic mosaicism in these 'simplex' cases (without family history of MEN1) cannot be ruled out [38]. Further, mutation negative patients have been reported to have later age at diagnosis of MEN1 tumours, milder disease course and longer median survival [26, 28, 39]. A similar scenario is presented in our study, though it did not tend to statistical significance.

Further, most studies describing the mutational spectrum among MEN1 patients usually report several novel mutations, a fact that has been reiterated in this study wherein $61 \%$ of the mutations were considered novel. This is also a pointer to the widely recognised feature among MEN1 which is the absence of mutational hotspots and phenotype-genotype correlation [24, 26, 36, 40, 41] 
corroborated by the varied spectrum of presentations and severity among the members of a single family $(F 1)$ in this study with a novel insertion (c.1151_1152insGAGG). The spectrum of mutations in this study ranged from frameshift to terminating mutations, again keeping in tune with literature in this area, though the absence of large deletions was certainly in contrast to that reported by Lemos et al. where $10 \%$ harbour such deletions [7]. This finding coupled with the absence of mutation in $\sim 44 \%$ of the definite index cases prompted us to look at other possibilities including mutations in the untranslated regions of MEN1 gene, CDKN1B and the CaSR genes; however, no mutations were found in these regions. Agarwal et al checked for CDKN1B mutations in 196 MEN1 mutation negative patients, and identified mutations in only $1.5 \%$ of those tested [42]. Mutation in CDKN1B is now recognised to be a rare cause of MEN1 like phenotype.

\section{Polymorphisms in MEN1, CDKN1B, and the CaSR genes}

Interestingly, several polymorphisms were seen in MEN1 mutants and non-mutants, the commonest being in exon 9 of the MEN1 gene (c.1269C > T;p.Asp423Asp). Among mutation negative patients, C.326T > G, P.V109G polymorphism in CDKN1B gene was found in 9 cases of definite MEN1 and two among MEN1-like patients. Patients $\geq 30$ years old carrying truncating MEN1 mutations and the c.326T > G(V109G) variant have been reported to have 18.3 times higher susceptibility to tumours in multiple glands (three to four glands) [43]. Also, the age at manifestation of the first aggressive tumour (pancreatic NET $>2 \mathrm{~cm}$ or any thoracic carcinoid tumour), and the time from diagnosis of MEN1 to the development of the first aggressive tumour have been found to be significantly shorter in MEN1 patients with CDKN1B V109G polymorphism [44]. Though benign, this change has been reported at an allele frequency ranging from 0.45 to 0.7 in population databases, for example, 1000 genome database. The role that these variants play in the absence of an exonic mutation is not clear, though speculative, the possibility of them serving as triggers for tumourigenesis cannot be ruled out. However, of note is the fact that the data from a meta-analysis on the role of this variant in a general population in the context of cancer development clearly showed no correlation between the presence of this variant and an overall risk of cancer, casting doubts on its role in MEN1 [45].

Finally, the utility of screening asymptomatic "at risk" first degree relatives cannot be emphasised more as shown by the four unaffected relatives ( $40 \%$ ) who were found to be positive for mutations. An early detection and subsequent thorough follow up could change the course of events and showcases the need to screen as many at risk individuals as possible.

There are a few limitations to this study including the fact that we have limited follow-up for these patients, and that many other genes (AIP, CDKN1A, CDKN2C, and CDKN2B) that could also carry mutations, albeit in very small percentages, were not included. In fact, several intronic mutations in the MEN1 gene have been described which may be significant in the absence of exonic mutations [40,46, 47]. With the advent of next generation sequencing many more genes can now be screened together, including a targeted panel that can cover for genes that might be rarely associated with MEN1. However, this study has the limitation of restricting genetic data to select genes and sequencing by Sangers method. Perhaps, a targeted panel that explores the most important genes associated with MEN1 or exome sequencing of the mutation negative definitive cases, might provide some answers.

\section{Conclusions}

Despite the limitations, this study has helped to capture in detail the clinical profile and provide an in-depth analysis on the mutational profile of patients with MEN1 from India, and will certainly help to overcome some lacunae in this area. The absence of MEN1 mutation in $\sim 44 \%$ of cases and the presence of p.V109G polymorphism in CDKN1B gene raises the question whether such polymorphisms could independently contribute to the pathogenesis.

\section{Author Contributions}

All authors contributed to the study conception and design. Data collection and analysis were performed by HSA and RP. The first draft of the manuscript was written by HSA and RP, and all authors commented on previous versions of the manuscript. All authors read and approved the final manuscript.

\section{Funding}

The study was funded by the Indian Council of Medical Research, Ref number 54/28/2012-HUM-BMS.

\section{Conflict of Interest}

The authors declare that they have no conflict of interest.

\section{References}

[1] Marini F, Giusti F, Brandi ML. Genetic test in multiple endocrine neoplasia type 1 syndrome: An evolving story. World J Exp Med 2015; 5: $124-129$

[2] Thakker RV, Newey P], Walls GV et al. Clinical practice guidelines for multiple endocrine neoplasia type 1 (MEN1). J Clin Endocrinol Metab 2012; 97: 2990-3011

[3] Kamilaris CDC, Stratakis CA. Multiple Endocrine Neoplasia Type 1 (MEN1): An update and the significance of early genetic and clinical diagnosis. Front Endocrinol (Lausanne) 2019; 10: 339

[4] Flanagan DE, Armitage M, Clein GP et al. Prolactinoma presenting in identical twins with multiple endocrine neoplasia type 1. Clin Endocrinol (Oxf) 1996; 45: 117-120

[5] Falchetti A. Genetics of multiple endocrine neoplasia type 1 syndrome: what's new and what's old. F1000 Res 2017; 6: F1000 Faculty Rev-F1000 Faculty R73

[6] Turner J], Christie PT, Pearce SH et al. Diagnostic challenges due to phenocopies: Lessons from Multiple Endocrine Neoplasia type1 (MEN1). Hum Mutat 2010; 31: E1089-E1101

[7] Lemos MC, Thakker RV. Multiple endocrine neoplasia type 1 (MEN1): Analysis of 1336 mutations reported in the first decade following identification of the gene. Hum Mutat 2008; 29: 22-32

[8] de Laat JM, van Leeuwarde RS, Valk GD. The Importance of an early and accurate MEN1 diagnosis. Front Endocrinol (Lausanne) 2018; 9: 533 
[9] Katznelson L, Laws ER Jr., Melmed S et al. Acromegaly: An endocrine society clinical practice guideline. J Clin Endocrinol Metab 2014; 99: 3933-3951

[10] Giustina A, Chanson P, Bronstein MD et al. A consensus on criteria for cure of acromegaly. J Clin Endocrinol Metab 2010; 95: 3141-3148

[11] Nieman LK, Biller BM, Findling JW et al. The diagnosis of Cushing's syndrome: An Endocrine Society Clinical Practice Guideline. J Clin Endocrinol Metab 2008; 93: 1526-1540

[12] Nieman LK, Biller BM, Findling JW et al. Treatment of Cushing's Syndrome: An Endocrine Society Clinical Practice Guideline. J Clin Endocrinol Metab 2015; 100: 2807-2831

[13] Chanson P, Raverot G, Castinetti F et al. Management of clinically nonfunctioning pituitary adenoma. Ann Endocrinol (Paris) 2015; 76: 239-247

[14] Melmed S, Casanueva FF, Hoffman AR et al. Diagnosis and treatment of hyperprolactinemia: An Endocrine Society clinical practice guideline. J Clin Endocrinol Metab 2011; 96: 273-288

[15] Cryer PE, Axelrod L, Grossman AB et al. Evaluation and management of adult hypoglycemic disorders: an Endocrine Society Clinical Practice Guideline. J Clin Endocrinol Metab 2009; 94: 709-728

[16] Fendrich V, Langer $P$, Waldmann J et al. Management of sporadic and multiple endocrine neoplasia type 1 gastrinomas. Br J Surg 2007; 94 : $1331-1341$

[17] Triponez F, Sadowski SM, Pattou F et al. Long-term Follow-up of MEN1 Patients Who Do Not Have Initial Surgery for Small $\leq 2 \mathrm{~cm}$ Nonfunctioning Pancreatic Neuroendocrine Tumors, an AFCE and GTE Study: Association Francophone de Chirurgie Endocrinienne \& Groupe d'Etude des Tumeurs Endocrines. Ann Surg 2018; 268: 158-164

[18] Corbo V, Dalai I, Scardoni M et al. MEN1 in pancreatic endocrine tumors: Analysis of gene and protein status in 169 sporadic neoplasms reveals alterations in the vast majority of cases. Endocr Relat Cancer 2010; 17: 771-783

[19] Tichomirowa MA, Lee M, Barlier A et al. Cyclin-dependent kinase inhibitor 1B (CDKN1B) gene variants in AIP mutation-negative familial isolated pituitary adenoma kindreds. Endocr Relat Cancer 2012; 19: 233-241

[20] Muddana V, Lamb J, Greer JB et al. Association between calcium sensing receptor gene polymorphisms and chronic pancreatitis in a US population: Role of serine protease inhibitor Kazal 1type and alcohol. World J Gastroenterol 2008; 14: 4486-4491

[21] Darling TN, Skarulis MC, Steinberg SM et al. Multiple facial angiofibromas and collagenomas in patients with Multiple endocrine neoplasia type 1. Arch Dermatol 1997; 133: 853-857

[22] Tonelli F, Marini F, Giusti F et al Total and Subtotal parathyroidectomy in young patients with Multiple endocrine neoplasia type 1- related primary hyperparathyroidism: Potential post-surgical benefits and complications. Front Endocrinol (Lausanne) 2018; 9: 558

[23] Sakurai A, Suzuki S, Kosugi S et al. Multiple endocrine neoplasia type 1 in Japan: Establishment and analysis of a multicentre database. Clin Endocrinol (Oxf) 2012; 76: 533-539

[24] Giraud S, Zhang CX, Serova-Sinilnikova O et al. Germ-line mutation analysis in patients with multiple endocrine neoplasia type 1 and related disorders. Am J Hum Genet 1998; 63: 455-467

[25] Cardinal JW, Bergman L, Hayward N et al. A report of a national mutation testing service for the MEN1 gene: Clinical presentations and implications for mutation testing. J Med Genet 2005; 42: 69-74

[26] Tham E, Grandell U, Lindgren $\mathrm{E}$ et al Clinical testing for mutations in the MEN1 gene in Sweden: a report on 200 unrelated cases. J Clin Endocrinol Metab 2007; 92: 3389-3395

[27] Goroshi M, Bandgar T, Lila AR et al. Multiple endocrine neoplasia type 1 syndrome: Single centre experience from western India. Fam Cancer 2016; 15: 617-624

[28] Pieterman CR, van Hulsteijn LT, den Heijer M et al. Primary hyperparathyroidism in MEN1 patients: a cohort study with longterm follow-up on preferred surgical procedure and the relation with genotype. Ann Surg 2012; 255: 1171-1178
[29] Montenegro FL, Lourenço DM Jr, Tavares MR et al. Total parathyroidectomy in a large cohort of cases with hyperparathyroidism associated with multiple endocrine neoplasia type 1: Experience from a single academic center. Clinics (Sao Paulo) 2012; 67: 131-139

[30] Trouillas ], Labat-Moleur F, Sturm N et al. Pituitary tumors and hyperplasia in multiple endocrine neoplasia type 1 syndrome (MEN1): A case-control study in a series of 77 patients versus 2509 non-MEN1 patients. Am J Surg Pathol 2008; 32: 534-543

[31] Shao QQ, Zhao BB, Dong LB et al. Surgical management of Zollinger-Ellison syndrome: Classical considerations and current controversies. World J Gastroenterol 2019; 25: 4673-4681

[32] Tonelli F, Giudici F, Nesi G et al. Operation for insulinomas in multiple endocrine neoplasia type 1 : When pancreatoduodenectomy is appropriate. Surgery 2017; 161: 727-734

[33] Challis BG, Casey RT, Grossman A et al. What is the appropriate management of nonfunctioning pancreatic neuroendocrine tumours disclosed on screening in adult patients with multiple endocrine neoplasia type 1? Clin Endocrinol (Oxf) 2019; 91: 708-715

[34] Lastoria S, Marciello F, Faggiano A et al. Role of (68)Ga-DOTATATE PET/ $\mathrm{CT}$ in patients with multiple endocrine neoplasia type 1 (MEN1). Endocrine 2016; 52: 488-494

[35] Ellard S, Hattersley AT, Brewer CM et al. Detection of an MEN1 gene mutation depends on clinical features and supports current referral criteria for diagnostic molecular genetic testing. Clin Endocrinol (Oxf) 2005; 62: 169-175

[36] Jäger AC, Friis-Hansen L, Hansen TV et al. Characteristics of the Danish families with multiple endocrine neoplasia type 1. Mol Cell Endocrinol 2006; 249: 123-132

[37] Backman S, Bajic D, Crona J et al. Whole genome sequencing of apparently mutation-negative MEN1 patients. Eur J Endocrinol 2020; 182: 35-45

[38] Falchetti A, Marini F, Luzi E et al. Multiple endocrine neoplasia type 1 (MEN1): not only inherited endocrine tumors. Genet Med 2009; 11: 825-835

[39] de Laat JM, van der Luijt RB, Pieterman CR et al. MEN1 redefined, a clinical comparison of mutation-positive and mutation-negative patients. BMC Med 2016; 14: 182

[40] Falchetti A. Genetic screening for multiple endocrine neoplasia syndrome type 1 (MEN-1): when and how. F1000 Med Rep 2010; 2: 14

[41] Marini F, Giusti F, Brandi ML. Multiple endocrine neoplasia type 1: extensive analysis of a large database of Florentine patients. Orphanet J Rare Dis 2018; 13: 205

[42] Agarwal SK, Mateo CM, Marx SJ. Rare germline mutations in cyclin-dependent kinase inhibitor genes in multiple endocrine neoplasia type 1 and related states [published correction appearead in]. J Clin Endocrinol Metab 2009; 94: 2674

[43] Longuini VC, Lourenço DM Jr., Sekiya T et al. Association between the p27 rs2066827 variant and tumor multiplicity in patients harboring MEN1 germline mutations. Eur J Endocrinol 2014; 171: 335-342

[44] Circelli L, Ramundo V, Marotta V et al. Prognostic role of the CDNK1B V109G polymorphism in multiple endocrine neoplasia type 1. J Cell Mol Med 2015; 19: 1735-1741

[45] Wei F, Xu J, Tang L et al. p27(Kip1) V109G polymorphism and cancer risk: a systematic review and meta-analysis. Cancer Biother Radiopharm 2012; 27: 665-671

[46] Carvalho RA, Urtremari B, Jorge AAL et al. Germline mutation landscape of multiple endocrine neoplasia type 1 using full gene next-generation sequencing. Eur J Endocrinol 2018; 179: 391-407

[47] Turner J], Leotlela PD, Pannett AA et al. Frequent occurrence of an intron 4 mutation in multiple endocrine neoplasia type 1. J Clin Endocrinol Metab 2002; 87: 2688-2693 